\title{
A prospective study on canine atopic dermatitis and food-induced allergic dermatitis in Switzerland
}

\author{
F. Picco*, E. Zini†, C. Nett‡, C. Naegeli§, \\ B. Biglerף, S. Rüfenacht**,§§, P. Roosje**, \\ M. E. Ricklin Gutzwiller**, S. Wilhelm*, \\ J. Pfistertt, E. Mengł‡ and C. Favrot* \\ *Clinic for Small Animal Internal Medicine, Dermatology Unit, \\ Vetsuisse Faculty, University of Zürich, Zürich, Switzerland \\ tClinic for Small Animal Internal Medicine, Vetsuisse Faculty, \\ University of Zürich, Zürich, Switzerland \\ ¥Small Animal Clinic Rigiplatz, Dermatology Unit, Cham, Switzerland \\ $\S$ Clinic for Small Animal, Balerna, Switzerland \\ ๆClinic for Small Animal and Laboratory Laupeneck, Bern, Switzerland \\ **Division of Clinical Dermatology, Department of Clinical Veterinary \\ Medicine, Vetsuisse Faculty, University of Bern, Bern, Switzerland \\ ††Clinic for Small Animal, Lausanne, Switzerland \\ ¥¥Small Animal Clinic Masans, Chur, Switzerland \\ $\S \S C l i n i c$ for Small Animal Aarau West, Oberentfelden, Switzerland \\ Correspondence: C. Favrot, Clinic for Small Animal Internal Medicine, \\ Dermatology Unit, Vetsuisse-Faculty, University of Zurich, \\ Winterthurerstrasse 260, CH-8057 Zurich, Switzerland. \\ E-mail: cfavrot@vetclinics.uzh.ch \\ The study was carried out as Dermfocus project (Dermfocus, \\ Vetsuisse Faculty, University of Bern, Bern, Switzerland)
}

What is known about the topic of this paper

- Atopic dermatitis and cutaneous adverse food reactions are common skin conditions in dogs.

- Food components may trigger flares of atopic dermatitis and some cases of cutaneous adverse food reactions manifest clinically like atopic dermatitis.

- Breed predispositions for atopic dermatitis have been demonstrated but may vary depending on geographical regions.

What this paper adds to the field of veterinary dermatology

- This is the first attempt to draw a population of allergic dogs from a whole canine population and to compare their characteristics.

- Swiss breed predispositions for atopic dermatitis but also for adverse food reactions are statistically demonstrated.

- An attempt is made to determine breed phenotypes of allergic dogs in Switzerland.

\begin{abstract}
Canine atopic dermatitis sensu stricto and food-induced allergic dermatitis are common canine skin conditions, which are often considered clinically undistinguishable. Several attempts have been made to describe populations of atopic dogs and determine breed predisposition but the results were often biased by the use of hospital populations as control group. The present study aims to describe a population of Swiss atopic and food-allergic dogs and to compare it with a data
\end{abstract}

set representing more than $85 \%$ of all Swiss dogs. The study, which was carried out during 1 year in several practices and teaching hospital in Switzerland, describes a group of 259 allergic dogs, determines breed predisposition for atopic dermatitis and food-induced allergic dermatitis, compares the clinical signs and features of both conditions, and outlines the clinical picture of five frequently affected breeds.

Accepted 26 February 2008

\section{Introduction}

Canine atopic dermatitis (CAD) is a genetically predisposed inflammatory and pruritic allergic skin disease with characteristic clinical features associated with lgE antibodies most commonly directed against environmental allergens. ${ }^{1}$ Genetic, immunological and environmental factors are consequently associated with the initial development and flares of the condition. ${ }^{2,3}$ Food components may also trigger flares of CAD and, consequently, some cases of cutaneous adverse food reactions (CAFR) manifest clinically as CAD. ${ }^{4}$ Canine AD sensu lato (CADsl) should therefore be regarded as a clinical diagnosis of a disease that may be triggered by several factors, including food components. One must, however, keep in mind that not all cases of CAFR exhibit clinical signs of CAD nor may have immunological causes. ${ }^{5}$ For the purposes of clarity in the rest of this article, we will use the term food-induced allergic dermatitis (FIAD) to describe cases of CAFR exhibiting clinical signs of CAD and the term CAD sensu stricto (CADss) for cases exhibiting clinical signs of CADsl which are not responsive to an elimination diet.

The clinical signs of CADsl are quite variable and there is no pathognomonic sign or feature that indicates the presence of the disease. Some typical findings have, however, been grouped into lists of criteria having a strong association with CAD. ${ }^{6,7}$ These lists should be considered in evaluation of pruritic dogs, keeping in mind that none of these sets of features are fully accurate for the diagnosis of CAD. ${ }^{8}$ One must thus rule out resembling diseases such as infestations with ectoparasites or primary bacterial infections. To further complicate the diagnosis, several factors such as breed, duration of the disease, and presence of secondary infections may influence the clinical picture $^{8-10}$ In order to better define the clinical signs and features of CAD, and especially, breed predispositions, several teams have described populations of atopic dogs. ${ }^{11-14}$ Unfortunately, predispositions have often been determined without any reference to the basic population, or in comparison with the hospital populations, which induces bias. 
The goal of the present study was to determine the clinical features of a population of Swiss dogs exhibiting clinical signs of CADss and FIAD. Taking advantage of the existence in Switzerland of the Animal Identity Service (ANIS), which claims to have registered more than $85 \%$ of all Swiss dogs, we have compared this population with atopic dogs diagnosed in eight different Swiss veterinary clinics or teaching hospitals by 11 dermatologically experienced veterinarians or specialists in the field. We have additionally compared clinical symptoms of dogs with CADss versus dogs with FIAD and attempted to determine breedassociated phenotypes in five frequently affected breeds.

\section{Material and methods}

\section{Swiss ANIS population}

Date of birth, sex and breed of all dogs registered at ANIS were collected. As all owners of dogs living in Switzerland are required by law to register their pet at ANIS, one may assume that the database is representative of the whole Swiss canine population.

\section{Patient selection and diagnostic evaluation}

Eleven veterinarians with extensive experience in veterinary dermatology, working in eight different veterinary clinics or teaching hospitals throughout Switzerland, included cases of CADss and FIAD for over 1 year (June 2006 to June 2007).

Dogs were included based on fulfilment of the Willemse's criteria. ${ }^{6}$ Similar dermatoses such as ectoparasites and primary bacterial infections were also ruled out.

In order to differentiate between FIAD and CADss, an elimination diet was carried out with home-cooked diet (horsemeat with potatoes) or, alternatively, selected commercial food (hypoallergenic $\operatorname{diet}^{1}$ ), for over 6 weeks. Dogs that improved during the trial were all challenged with previously fed foods. A definitive diagnosis of FIAD was made based on the recurrence of clinical signs upon food challenge.

\section{Outcome evaluations}

Breed and sex of selected dogs were compared to the ANIS population. The analysis was first made for the whole population of CADsl dogs, then for CADss and FIAD dogs, separately. The following clinical signs and features were evaluated by the investigators in all selected dogs and recorded on a standard form: age at onset, presence of pruritus 'sine material' at onset, seasonality (defined as occurrence or exacerbation of the signs during spring or summer), localization of the lesions, presence of secondary bacterial and yeast infections (assessed by cytological examination), presence of otitis externa, onset of otitis externa before or after other clinical signs, interdigital fistulae and/or interdigital pyoderma, pyotraumatic dermatitis, urticaria, angioedema, seasonal conjunctivitis or sneezing, gastrointestinal disturbances (diarrhoea, vomiting, tenesmus, soft stools, increased faecal frequency: information collected by questioning the owners), oily or dry seborrhea, and response to glucocorticoid therapy.

In order to uncover potential differences between CADss and FIAD dogs, both populations were compared. As some reports mentioned that young atopic dogs first developed seasonal signs, an attempt was made to correlate age with seasonality.

In CADss dogs, the frequency of seasonality in each age group (< 6 months of age; $<1$ year old; $<3$ years old: $>3$ years old) was studied and compared to the other age groups.

Additionally, five breeds (West Highland white terrier (WHWT), German shepherd dog, boxer, Labrador and golden retriever) were selected for further evaluation because of the high number of affected dogs. The same clinical features were compared in an attempt to determine breed-associated phenotypes.

${ }^{1}$ Royal Canin, Sensitivity Control with Capelin and Tapioca or Hypoallergenic diet from Royal Canin or Hypoallergenic diet from Purina or from Hill's z/d or from Swiss Animal Food Sensidog.

\section{Statistical analysis}

Data analysis was performed with GraphPad Prism version 4.0 (GraphPad Software, San Diego, CA, USA). Proportions of the above listed clinical signs and features were first compared, grouping dogs with CADss and FIAD versus the healthy canine population, and then separately considering the two diseases. Proportions were also compared between dogs affected by CADss or FIAD. Analysis was achieved with chi-square test or Fisher's exact test followed by Bonferroni correction. Significance was set at a $P$-value of $\leq 0.05$. Significance without Bonferroni correction is sometimes mentioned in tables or in the text, when the authors considered that this feature may provide some valuable information, i.e. trends. The determination of breed-associated phenotype was carried out with the same statistical tools. Each breed was compared to the whole population of affected dogs.

\section{Results}

\section{ANIS Swiss population}

The original Swiss dog dataset consisted of 418422 microchipped dogs.

There were 205543 (50.6\%) males, 211786 (49.1\%) females. The sex was not determined for 1147 (0.3\%).

\section{Study population}

The study ran from June 2006 to June 2007 and a total of 259 allergic dogs were included. Of these 259 affected dogs, 183 (70.7\%) suffered from CADss while 65 (25.1\%) were afflicted with FIAD and 11 dogs $(4.2 \%)$ responded only partially to an elimination diet or were diagnosed as suffering from both conditions.

\section{Comparison between the study population and the ANIS population}

Breed predispositions have been studied for the whole study group $(n=259)$, for CADss dogs $(n=183)$ and for FAD dogs $(n=65)$; results are summarized in Table 1a-c. The following breeds are predisposed for CADsl: WHWT, boxer, French bulldog, Vizsla, bullterrier and Rhodesian ridgeback. Additionally, pugs and Dalmatians were overrepresented in the study group but without any significance after Bonferroni correction. When one considers CADss, WHWT, boxer, French bulldog, bullterrier, Vizsla and basset are predisposed. Once more, Dalmatians were also overrepresented in this group. On the other hand, WHWT, boxers, Rhodesian ridgebacks and pugs were predisposed for the development of FIAD. Additionally, German shepherd dogs were at higher risk for the development of FIAD when the data were considered without Bonferroni corrections.

The Yorkshire terrier, standard poodle, Bernese mountain dog, Appenzeller dog and border collie breeds had reduced incidences of CADsl. There were 122 female $(47 \%)$ and 137 male dogs (53\%) in the study group. These percentages were not statistically significantly different when compared to the ANIS population. It is, however, worth noting that male Labradors have a tendency to be overrepresented (17 of $22, P<0.07$ ) in the CADss group.

\section{Comparison between CADss and FIAD dogs}

Clinical signs and features were analysed in both groups and are presented in Table 2. Statistical differences were found for age at onset, seasonality, gastrointestinal signs and the occurrence of yeast infections.

Sixteen percent of the dogs in the CADss group exhibited clinical signs before 1 year of age and $78 \%$ were younger 
Table 1. (a) CAD dogs (whole study group): frequently affected breeds

\begin{tabular}{|c|c|c|c|c|}
\hline \multirow[b]{2}{*}{ Breed } & \multicolumn{2}{|c|}{ Patient population } & \multicolumn{2}{|c|}{ Swiss population } \\
\hline & Number & Percentage & Number & Percentage \\
\hline West Highland white terrier** & 30 & 11.6 & 8435 & 2 \\
\hline Mixed & 30 & 11.6 & 34124 & 8.2 \\
\hline Labrador & 22 & 8.5 & 34596 & 8.3 \\
\hline Boxer** & 18 & 6.9 & 4675 & 1.1 \\
\hline Golden retriever & 18 & 6.9 & 18385 & 4.4 \\
\hline German shepherd & 15 & 5.8 & 18472 & 4.4 \\
\hline French bulldog** & 6 & 2.3 & 1266 & 0.3 \\
\hline Bullterrier** & 5 & 1.9 & 513 & 0.1 \\
\hline Dalmatian* & 5 & 1.9 & 2854 & 0.7 \\
\hline Jack Russel terrier & 5 & 1.9 & 12973 & 3.1 \\
\hline Vizsla** & 5 & 1.9 & 360 & 0.1 \\
\hline Rhodesian ridgeback** & 4 & 1.5 & 949 & 0.3 \\
\hline Chihuahua & 4 & 1.5 & 3732 & 0.9 \\
\hline Pug* & 4 & 1.5 & 1611 & 0.4 \\
\hline
\end{tabular}

* Statistical significance without Bonferroni correction $(P<0.05)$.

** Statistical significance with Bonferroni correction $(P<0.05)$.

(b) Canine atopic dermatitis sensu stricto (CADss): frequently affected breeds

\begin{tabular}{|c|c|c|c|c|}
\hline \multirow[b]{2}{*}{ Breed } & \multicolumn{2}{|c|}{ Patient population } & \multicolumn{2}{|c|}{ Swiss population } \\
\hline & Number & Percentage & Number & Percentage \\
\hline West Highland white terrier** & 22 & 12 & 8435 & 2 \\
\hline Mixed & 21 & 11.5 & 34124 & 8.2 \\
\hline Labrador & 15 & 8.2 & 34596 & 8.3 \\
\hline Boxer** & 15 & 8.2 & 4675 & 1.1 \\
\hline Golden retriever & 12 & 6.6 & 18385 & 4.4 \\
\hline German shepherd & 7 & 3.8 & 18472 & 4.4 \\
\hline French bulldog** & 5 & 2.7 & 1266 & 0.3 \\
\hline Bullterrier** & 4 & 2.2 & 513 & 0.1 \\
\hline Dalmatian* & 4 & 2.2 & 2854 & 0.7 \\
\hline Jack Russel terrier & 4 & 2.2 & 12973 & 3.1 \\
\hline Vizsla** & 4 & 2.2 & 360 & 0.1 \\
\hline Basset ${ }^{*}$ & 3 & 1.6 & 297 & 0.1 \\
\hline
\end{tabular}

* Statistical significance without Bonferroni correction $(P<0.05)$.

**Statistical significance with Bonferroni correction $(P<0.05)$.

(c) Dogs with food-induced allergic dermatitis: frequently affected breeds

\begin{tabular}{|c|c|c|c|c|}
\hline \multirow[b]{2}{*}{ Breed } & \multicolumn{2}{|c|}{ Patient population } & \multicolumn{2}{|c|}{ Swiss population } \\
\hline & Number & Percentage & Number & Percentage \\
\hline West Highland white terrier** & 8 & 12.3 & 8435 & 2 \\
\hline Mixed & 6 & 9.2 & 34124 & 8.2 \\
\hline Labrador & 6 & 9.2 & 34596 & 8.3 \\
\hline German shepherd* & 6 & 9.2 & 18472 & 4.4 \\
\hline Golden retriever & 5 & 7.7 & 18385 & 4.4 \\
\hline Pug** & 4 & 6.2 & 1611 & 0.4 \\
\hline Boxer** & 3 & 4.6 & 4675 & 1.1 \\
\hline Rhodesian ridgeback** & 3 & 4.6 & 949 & 0.3 \\
\hline
\end{tabular}

* Statistical significance without Bonferroni correction $(P<0.05)$.

** Statistical significance with Bonferroni correction $(P<0.05)$.

than 3 years at clinical onset of disease. In the FIAD group initial clinical symptoms occurred before 1 year of age in $48 \%$ and before 3 years of age in $83 \%$. The former figure is statistically significant $(P<0.03)$ compared to the CADss group.

As expected, seasonality was not present in FIAD dogs. On the contrary, 64 (35\%) dogs with CADss exhibited seasonality. Fifty-nine (92\%) of the seasonally affected dogs exhibited clinical signs in spring and/or summer and five (8\%) during winter. There was no correlation between the age of the affected dogs and the seasonality.
Furthermore, the occurrence of gastrointestinal signs and yeast infections was far more frequent in FIAD dogs than in CAD dogs $(P<0.0001$ and $P<0.0002$, respectively).

\section{Attempts to determine breed phenotypes}

In an attempt to uncover breed-associated phenotypes, the clinical features and signs of the five most frequently affected breeds were compared. For each breed, the number of dogs affected with one specific feature was compared with the whole group. Results are summarized in Table 3. 
Table 2. Clinical signs and features of dogs with canine atopic dermatitis sensu stricto (CADss) and dogs with food-induced allergic dermatitis (FIAD)

\begin{tabular}{|c|c|c|c|c|}
\hline \multirow[b]{2}{*}{ Clinical sign } & \multicolumn{2}{|c|}{ CADss dogs $(n=183)$} & \multicolumn{2}{|c|}{ FIAD dogs $(n=65)$} \\
\hline & Number & Percentage & Number & Percentage \\
\hline Cortico-responsive pruritus & 153 & 84 & 48 & 74 \\
\hline Chronic or recurrent otitis externa & 80 & 44 & 36 & 55 \\
\hline$\rightarrow$ First episode before other signs & 43 & 23 & 22 & 34 \\
\hline$\leftarrow$ First episode concomitant or after & 29 & 16 & 10 & 15 \\
\hline Previous episode of hot spots & 18 & 1 & 7 & 11 \\
\hline Concomitant interdigital fistula & 24 & 13 & 14 & 22 \\
\hline Chronic diarrhoea/vomiting & 18 & 1 & $20^{*}$ & 31 \\
\hline Affected front feet & 137 & 75 & 43 & 66 \\
\hline Affected hind feet & 126 & 69 & 42 & 65 \\
\hline Affected axillae & 117 & 64 & 34 & 52 \\
\hline Affected abdomen/inguinal areas & 119 & 65 & 34 & 52 \\
\hline Affected lips & 61 & 33 & 23 & 35 \\
\hline Affected eyelids & 50 & 27 & 15 & 23 \\
\hline Affected elbow & 39 & 21 & 16 & 36 \\
\hline Affected dorso lumbar & 28 & 15 & 16 & 36 \\
\hline Chronic bacterial infection & 118 & 64 & 43 & 66 \\
\hline Chronic yeast infection & 36 & 20 & $28^{*}$ & 43 \\
\hline
\end{tabular}

* Statistical significance with Bonferroni correction $(P<0.05)$.

Table 3. Frequency of clinical signs and features of four canine atopic dermatitis sensu lato (CADsl) frequently affected breeds: Statistical comparison with the whole group of allergic dogs (259 dogs)

\begin{tabular}{|c|c|c|c|c|c|}
\hline Clinical sign percentage & $\begin{array}{l}\text { WHWT } \\
n=30\end{array}$ & $\begin{array}{l}\text { Labrador retriever } \\
n=22\end{array}$ & Boxer $n=18$ & $\begin{array}{l}\text { Golden retriever } \\
n=18\end{array}$ & $\begin{array}{l}\text { German shepherd } \\
n=15\end{array}$ \\
\hline \multicolumn{6}{|l|}{ Age at onset } \\
\hline$<1$ year old & 27 & 36 & 56 & 33 & 53 \\
\hline$<3$ years old & 73 & 82 & 89 & 67 & 93 \\
\hline$>3$ years old & 27 & 18 & 11 & 33 & 7 \\
\hline Cortico-responsive pruritus & 77 & 77 & 67 & $89 * *$ & $87^{* *}$ \\
\hline Pruritus sine materia at onset & 67 & 55 & 56 & 61 & 67 \\
\hline Chronic or recurrent otitis externa & 60 & 45 & 67 & 50 & 60 \\
\hline Conjunctivitis & 20 & 32 & 33 & 11 & 40 \\
\hline Seasonality & 27 & 36 & 11 & 28 & 13 \\
\hline Seborrhea oleosa & $27^{* *}$ & 5 & 11 & 0 & $40 * *$ \\
\hline Previous episode of hot spot & 7 & $27^{* *}$ & 0 & $28 * *$ & 7 \\
\hline Interdigital fistula & 20 & $32 * *$ & 11 & 6 & 13 \\
\hline Affected front feet & 90 & 77 & 83 & $50^{*}$ & 80 \\
\hline Affected hind feet & 83 & 77 & 83 & 56 & 73 \\
\hline Affected axillae & 57 & 55 & 44 & 83 & 67 \\
\hline Affected abdomen/inguinal & 60 & 50 & 72 & 72 & 73 \\
\hline Affected genitalia/ventral tail & 53 & 32 & 28 & 56 & 47 \\
\hline Affected lips & 43 & 23 & 39 & 50 & 47 \\
\hline Affected dorso lumbar & $37^{* *}$ & 9 & 0 & 33 & 0 \\
\hline Secondary bacterial infections & $90 * *$ & 64 & 72 & 67 & $100 * *$ \\
\hline Secondary yeast infections & $67^{* *}$ & 36 & $83 * *$ & 28 & $67 * *$ \\
\hline
\end{tabular}

${ }^{*}$ Statistical significance without Bonferroni correction $(P<0.05)$.

** Statistical significance with Bonferroni correction $(P<0.05)$.

WHWT, West Highland white terrier.

Golden retriever and German shepherd dogs seemed to be more responsive to glucocorticoid therapy than the other breeds. Furthermore, WHWT and German shepherd dogs showed seborrhoea oleosa in association with CAD significantly more often compared to the whole group. This feature could explain the predisposition of these breeds to both yeast and bacterial infections. Boxers were also predisposed to yeast infections. Regarding distribution, WHWT were more often affected with pododermatitis of the front feet, whereas golden retrievers were less often affected. WHWT and golden retrievers sometimes presented with lesions on the dorso-lumbar areas. Labrador and golden retrievers were more often affected by pyotraumatic pyoderma, whereas WHWT were less often affected than other breeds. Labrador retrievers also frequently presented with interdigital fistulae in association with CADsl.

\section{Discussion}

We have taken advantage of the existence of an animal database to carry out this cross-sectional study of Swiss 
allergic dogs. This study contributes to describe some breed-associated allergic phenotypes to confirm that only some minor differences exist in the clinical presentation of dogs suffering FIAD and CADss and to determine breed predispositions.

Reliable evaluation of breed predispositions for veterinary diseases is complicated by the fact that the population at risk is often unknown. Several studies have, however, addressed the question of breed predisposition for CAD. ${ }^{3}$ Some studies only mentioned the most frequently represented breeds while some others have been based on a comparison between atopic dogs and the hospital or insurance population. 9,11,12,14-18 The former do not present any statistical analysis and the latter may be biased by the absence or the underrepresentation of healthy dogs. One single study is based on a large population of insured dogs but contains another potential bias: the authors did not make the diagnosis of CAD themselves but referred to the diagnosis of general practitioners, who may have used variable inclusion criteria. ${ }^{12}$ To further complicate the analysis, predisposed breeds may vary by geographical areas. ${ }^{19,20}$ Some breeds such as WHWT, boxers, golden retrievers or Labrador retrievers are, however, mentioned in virtually all these studies. Some others such as German shepherd dogs seem to be predisposed for CAD only in some geographical regions.

The Swiss dog population is unique in that all dogs' owners are required by law to microchip or tattoo their dogs and to register them in a central database. The data set is consequently likely to be representative of the population of Swiss atopic dogs. The authors, who worked in eight different practices throughout Switzerland, have recorded the clinical features and signs of confirmed cases of CADss and/or FIAD. Interestingly, three breeds that are often considered overrepresented do not appear to be predisposed in our study: Labrador, golden retriever and German shepherd dogs. It is worth noticing, however, that dogs belonging to these breeds were frequently diagnosed with CADss and/or FIAD because they are also very popular breed in Switzerland.

Our study confirms that some breeds, such as WHWT, boxer, French bulldog or bullterrier, are also predisposed to CAD in Switzerland. To the best of our knowledge, breed predisposition for FIAD have not been firmly demonstrated previously, even if some breeds were considered at risk: boxer, cocker and Springer spaniel, collies, Dalmatian, German shepherd dogs, Lhasa apso, Miniature schnauzer, retriever, shar pei, dachshund and WHWT., 21-23 In Switzerland, WHWT, pugs, boxer, Rhodesian ridgeback, and to a lesser extent, German shepherd dogs are predisposed breeds for this condition. Twenty-five percent of our study population were affected by FIAD. Several other studies have shown that $7-26 \%$ of dogs with clinical signs compatible with CADss or FIAD were affected by FIAD. ${ }^{2,24-30}$ Our results, even if relatively high, are completely in line with the previous reports. It is also worth noticing that using commercial diets in some dogs could have reduced the number of FIAD diagnoses as well as the number of dogs with both FIAD and CADss. Our study has also confirmed that CADss and FIAD are often clinically indistinguishable. FIAD is sometimes said to be less responsive to corticosteroid treatment but this assumption was not confirmed in our study. ${ }^{21,24}$ On the other hand, our study has demonstrated that FIAD dogs are prone to yeast infections and gastrointestinal signs. The latter feature was already frequently recorded but the former was never shown and probably reflects differences in breed predisposition. Last but not least, our study confirms that FIAD dogs are usually younger than CADss dogs at onset of clinical disease.

In contrast with FIAD, clinical signs of CADss can be seasonal or nonseasonal. The seasonality rate found in this investigation was higher (37\%) than reported in the literature. $9,11,13,31$ However, initial signs of CADss are reported to be seasonal in $42-75 \%$ of dogs. ${ }^{19,32,33}$ We were not able to confirm this assumption. Canine AD is often considered as a good model for its human counterpart, which is known to be associated with several mutations. ${ }^{34}$ It seems consequently logical and tempting to hypothesize that the variability of the clinical features presented by atopic patients could be due to variable genetic make-ups. In this regard, we have recorded the features of CAD dogs belonging to the five most frequently affected breeds. Although the number of dogs in each group is too low to draw some definitive conclusions, this study outlines the clinical pictures of five CAD-affected breeds.

The study contributes to better characterize the population of Swiss allergic dogs. Further studies, including more animals in a larger geographical area, are however, required to assess whether our findings may be extended to other groups and to better define breed-associated phenotypes.

\section{Acknowledgements}

This study was carried out with the support of NOVARTIS Animal Health, Basel, Switzerland. The authors would like to thank ANIS AG, Bern, Switzerland for their support.

\section{References}

1. Halliwell R. Revised nomenclature for veterinary allergy. Veterinary Immunology and Immunopathology 2006; 114: 207-8.

2. Hillier A, Griffin CE. The ACVD task force on canine atopic dermatitis (1): incidence and prevalence. Veterinary Immunology and Immunopathology 2001; 81: 143-6.

3. Sousa CA, Marsella R. The ACVD task force on canine atopic dermatitis (2): genetic factors. Veterinary Immunology and Immunopathology 2001; 81: 153-7.

4. Olivry T, DeBoer DJ, Prélaud P et al. Food for thought: Pondering the relationship between canine atopic dermatitis and cutaneous adverse food reactions. Veterinary Dermatology 2007; 18: 390-1.

5. Verlinden A, Hesta M, Millet S et al. Food allergy in dogs and cats: a review. Critical Reviews in Food Science and Nutrition 2006; 46 259-73.

6. Willemse T. Atopic skin disease: a review and a consideration of diagnostic criteria. Journal of Small Animal Practice 1986; 27: $771-$ 8.

7. Prélaud $P$, Guaguère $E$, Alhaidari Z et al. Revaluation of diagnostic criteria of canine atopic dermatitis. Revue Médicale Vétérinaire 1998; 149: 1057-64.

8. DeBoer DJ. The ACVD task force on canine atopic dermatitis (15): fundamental concepts in clinical diagnosis. Veterinary Immunology and Immunopathology 2001; 81: 271-6.

9. Tarpataki N, Papa K. Prevalence and features of canine atopic dermatitis in Hungary. Acta Veterinaria Hungarica 2006; 54: 35366.

10. Prélaud P. Atopic canine dermatitis: breed-related features. Pratique médicale et chirurgicale de l'animal de compagnie 2001, 309-16. 
11. Saridomichelakis MN, Koutinas AF, Gioulekas D. Canine atopic dermatitis in Greece: clinical observations and the prevalence of positive intradermal test reactions in 91 spontaneous cases. Veterinary Immunology and Immunopathology 1999; 69: 61-73.

12. Nodtvedt A, Bergvall $K$, Emanuelson U et al. Canine atopic dermatitis: validation of recorded diagnosis against practice records in 335 insured Swedish dogs. Acta Veterinaria Scandinavica 2006; 48: 8.

13. Zur G, Ihrke PJ, White SD et al. Canine atopic dermatitis: a retrospective study of 266 cases examined at the University of California, Davis, 1992-98. Part I. Clinical features and allergy testing results. Veterinary Dermatology 2002; 13: 89-102.

14. Nodtvedt A, Engenvall A, Bergvall K. Incidence of and risk factors for atopic dermatitis in a Swedish population of insured dogs. Veterinary Record 2006; 159: 241-6.

15. Willemse A, van den Brom WE. Investigation of the symptomatology and the significance of immediate skin test reactivity in canine atopic dermatitis. Veterinary Research 1983; 34: 261-5.

16. Carlotti DN, Costargent F. Analysis of positive skin tests in 449 dogs with allergic dermatitis. European Journal of Companion Animal Practice 1994; 4: 42-59.

17. Sture GH, Halliwell REW, Thoday KL et al. Canine atopic disease: the prevalence of positive intradermal skin tests at two sites in the north and south of Great Britain. Veterinary Immunology and Immunopathology 1995; 44: 293-308.

18. Koch HJ, Peters S. 207 Intrakutantests bei Hunden mit Verdacht auf atopische Dermatitis. Kleintierpraxis 1994; 39: 25-36.

19. Griffin CE, DeBoer DJ. The ACVD task force on canine atopic dermatitis (14): clinical manifestations of canine atopic dermatitis. Veterinary Immunology and Immunopathology 2001; 81: 255-69.

20. Nodtvedt A, Guitan J, Egenvall A et al. The spatial distribution of atopic dermatitis cases in a population of insured Swedish dogs. Preventive Veterinary Medicine 2007; 78: 210-22.

21. Rosser EJ. Diagnosis of food allergy in dogs. Journal of the American Veterinary Medical Association 1993; 203: 259-62.
22. Walton GS. Skin responses in the dog and cat to ingested allergens. The Veterinary Record 1967; 81: 709-13.

23. White SD. Food hypersensitivity in 30 dogs. Compendium on Continuing Education for the Practicing Veterinarian 1986; 20 : 261-8.

24. Wilhelm S, Favrot C. Food hypersensitivity dermatitis in the dog: diagnostic possibilities. Schweizerisches Archiv für Tierheilkunde 2005; 147: 165-71

25. Scott DW, Paradis M. A survey of canine and feline skin disorders seen in a university practice: small animal clinic, University of Montréal, Saint-Hacinthe, Québec (1987-88). Canadian Veterinary Journal 1990; 31: 830-5

26. Hill PB, Eden CAN, Huntley S et al. Survey of the prevalence, diagnosis and treatment of dermatological conditions in small animals in general practice. Veterinary Record 2006; 158: 533-9.

27. DeBoer DJ. Survey of intradermal skin testing practices in North America. Journal of American Veterinary Medical Association 1989; 195: 1357-63.

28. Chesney CJ. Systemic review of evidence for the prevalence of food sensitivity in dogs. Veterinary Record 2001; 148: 445-8.

29. Chesney CJ. Food sensitivity in the dog: a quantitative study. Journal of Small Animal Practice 2002; 43: 203-7.

30. Kunkle GA, Horner S. Validity of skin testing for diagnosis of food allergy in dogs. Journal of American Veterinary Medical Association 1992; 200: 677-80.

31. Scott DW, Miller WH, Griffin CE. Small Animal Dermatology, 6th edn. Philadelphia, PA: W.B. Saunders, 2001: 543-666.

32. Halliwell REW, Schwartzman RM. Atopic disease in the dog. Veterinary Record 1971; 89: 209-14.

33. Scott DW. Observations on canine atopy. Journal of American Animal Hospital Association 1981; 17: 91-100.

34. Morar N, Willis-Owen SA, Moffatt MF et al. The genetics of atopic dermatitis. Journal of Allergy and Clinical Immunology 2006; 118 : 24-34.

Résumé La dermatite atopique canine au sens strict et l'allergie alimentaire sont des maladies fréquentes chez le chien, qui se ressemblent souvent. Différents essais ont été réalisés pour décrire les populations de chiens atopiques et pour déterminer une prédisposition raciale, mais les résultats sont souvent biaisés par l'utilisation de populations de malades comme groupes contrôles. Cette étude vise à décrire une population de chiens suisses atopiques ou allergiques alimentaires et de les comparer avec une base de données correspondant à $85 \%$ de tous les chiens de Suisse. Cette étude, qui a été réalisée dans plusieurs cliniques et écoles vétérinaires sur une période de un an, décrit un groupe de 259 chiens allergiques, détermine les prédispositions raciales pour la dermatite atopique et l'allergie alimentaire, compare les signes cliniques des deux maladies et souligne les signes cliniques chez cinq races fréquemment atteintes.

Resumen La dermatitis atópica canina en sentido estricto y la dermatitis alérgica inducida por alimentos son proces comunes en la piel de perros, tradicionalmente no diferenciables en base a presentación. Se han producido diversos intentos de describir poblaciones de perros atópicos y determinar una predisposición de raza, pero los resultados eran a menudo desviados por el uso de animales de hospitales de referencia como grupos control. Este estudio describe una población de perros Suizos atópicos y perros con dermatitis alérgica a alimentos y los compara con una población que representa más del $85 \%$ de todos los perros suizos. El estudio, llevado a cabo durante un año en varios hospitales clínicos y de universidades, describe un grupo de 259 perros alérgicos, determina la predisposición a dermatisis atópica y alimentaria de diferentes razas, y compara los signos clínicos y características de ambas condiciones, resaltando el cuadro clínico de las cinco razas afectadas con mayor frecuencia.

Zusammenfassung Die canine atopische Dermatitis im engeren Sinn und die durch Futtermittel induzierte allergische Dermatitis stellen häufige Hautprobleme beim Hund dar, die oft klinisch als nicht unterscheidbar gelten. Es sind bereits mehrere Versuche unternommen worden, um Populationen von atopischen Hunden zu beschreiben und eine Rassenprädisposition zu bestimmen. Die Ergebnisse waren jedoch oft durch die Verwendung einer Klinikpopulation als Kontrollgruppe einseitig beeinflusst. Das Ziel der vorliegenden Studie war es, eine Population von atopischen und Futtermittel-allergischen Hunden aus der Schweiz zu beschreiben und sie mit einem Datensatz, welcher mehr als 85\% aller Hunde der Schweiz repräsentierte, zu vergleichen. Die Studie, die im Laufe eines Jahres in verschiedenen Praxen und Universitätstierkliniken der Schweiz durchgeführt wurde, beschreibt eine Gruppe von 259 allergischen Hunden, bestimmt die Rassenprädisposition für die atopische Dermatitis und die Futtermittel induzierte allergische Dermatitis, vergleicht die klinischen Symptome und besonderen Merkmale beider Krankheitsbilder und fasst das klinische Bild von fünf häufig betroffenen Rassen kurz zusammen. 